\title{
How job insecurity affects emotional exhaustion? A study of job insecurity rumination and psychological capital during COVID-19.
}

Research Article

Marta Konkel, Margaret Heffernan*

DCU Business School, Dublin City University, Glasnevin, Dublin, Ireland

Abstract: Drawing on conservation of resources theory (COR), this study takes a nuanced approach to understanding job insecurity by proposing rumination as a mediator in its relationship with well-being during the COVID-19 global pandemic. The moderating role of psychological capital as a resource to buffer this negative relationship is also explored. A cross sectional study of employees in Ireland during the early months of the COVID-19 pandemic found that job insecurity rumination mediated the relationship between affective job insecurity and emotional exhaustion. There was no support for the hypothesis that psychological capital could moderate the relationship between job insecurity and emotional exhaustion. Thus, this research advances the job insecurity literature by identifying a potential mediator and moderator in the process of how employees may experience job insecurity particularly during a global pandemic.

Keywords: Job insecurity; emotional exhaustion; COVID-19; job insecurity rumination; psychological capital

(C) Sciendo

\section{INTRODUCTION}

For years the workplace has been increasingly characterised by transformative technology, climate, political and economic changes, globalisation, and demography (Balliester and Elsheikhi, 2018), all of which can be seen as contributors of uncertainty among employees. The sudden onset of the COVID-19 pandemic in early 2020 has seen this uncertainty escalate even further. This uncertainty encompassed almost every aspect of the COVID-19 crisis, from the infectiousness of the virus; its lethality, the vaccine development and deployment timeline, the short-term economic impact of the pandemic through to the potential speed of economic recovery post pandemic (Altig et al., 2020). As a result of this economic uncertainty, there is increased employment uncertainty for employees.

Data for this study was collected during the early months of the COVID-19 pandemic in Ireland during its first lockdown (March to May 2021). The initial period of the COVID-19 pandemic in Ireland resembles very much the experience of many other European countries. Ireland had its first confirmed COVID-19 case on 29 February 2020. From that date, the number of confirmed infections began to increase. On 12 March the first stages of lockdown were introduced with all schools, colleges, childcare facilities and cultural institutions closing and all large gatherings being cancelled. The Tánaiste at the time, Simon Coveney, when introducing these measures stated "the irony is that, in order to pull together in the country, now we are asking Irish people to stay apart". On 24 March 2020 almost all businesses, venues and amenities were shut with workers told to work from home. This was closely followed on 27 March with strict lockdown measures being introduced culminating in all non-essential travel and contact with people being banned. The Republic of Ireland's first lockdown was the longest in Europe, especially for construction, hospitality and retail, resulting in the largest monthly increase in unemployment in the history of the State during March 2020 (Coates, et al., 2020). A Pandemic Unemployment Payment (PUP) and a Temporary 
Wage Subsidy Scheme was set up to support employees working in affected sectors as a means to buffer the negative effects of the pandemic. Therefore, the uncertainty around employment and job security during this time was immense.

Job insecurity is a subjective phenomenon (Sverke et al., 2002) and its negative impacts can vary among employees. It is therefore interesting to examine how employees appraise job insecurity as a work stressor in light of current events. Considering the increasing trend of job insecurity among employees, further heightened by the impact of COVID-19 on the global economy, this paper seeks to examine the impact of job insecurity on emotional exhaustion through the exploration of a new mechanism, job insecurity rumination. Job insecurity rumination can affect employees' ability to recover from work through the cognitive process of ruminating about one's job loss during a stressful situation (such as experiencing job insecurity during a pandemic). As a result, the repetitive thoughts about the uncertain future of their employment deflate their ability to preserve resources, eventually leading to emotional exhaustion (Richter et al., 2020). The context of COVID-19, with the continued uncertainty around the behaviour of the virus, widespread restrictions in business and non-stop media coverage, has exacerbated this uncertainty indicating that job insecurity rumination may be a significant variable to explore in job insecurity research.

Past research by Richter and Naswall (2019) suggested future studies should explore potential psychological factors that can buffer the adverse effect of job insecurity. Hence, to further contribute to the existing research on job insecurity and employee well-being during COVID-19, this study aims to examine the moderating role of positive psychological capital (PsyCap) on the job insecurity-emotional exhaustion relationship. In previous research, psychological capital has been shown to moderate the relationship between job insecurity and performance outcomes (e.g. Probst et al., 2017). Therefore, the aim is to examine whether it will have the same effect on the relationship between job insecurity and emotional exhaustion.

This study contributes to the existing job insecurity literature in several ways. Firstly, we respond to recent calls to apply a process lens to more clearly elucidate the psychological processes and impacts of job insecurity (Lee et al., 2018). In doing so, we introduce job insecurity rumination as a mechanism that could explain further the relationship between job insecurity and emotional exhaustion. Drawing on the Conservation of Resources (Hobfoll, 2001) theory, we predict that job insecurity depletes employees' resources through repetitive thoughts and worries about the future of their job. Previous job insecurity research has drawn on cognitive perspectives such as social exchange theory and the psychological contract more explicitly (DeCuyper and De Witte 2006) or appraisal theory of stress (König et al. 2011). Given the uncertainty of COVID-19, we argue the need to take account of the emotional and behavioural intensification of an employee's job insecurity experience via rumination. Rumination can be characterised by self-reflection as well as a repetitive and passive focus on one's negative emotions (NolenHoeksema et al., 2008) which has been shown to have a negative impact including depression.

Second, we study the relationship between job insecurity and employees well-being (namely emotional exhaustion) in the context of a prolonged health emergency and an economic crisis. Previous studies have investigated job insecurity during a financial crisis (Adkins et al., 2001) but not in a time of a major global economic, psychosocial and social disruption. The unprecedented nature of COVID-19's transmissibility, lethality, and disruptiveness creates an important context for examining whether and how job insecurity impacts on employee well-being during a crisis. Third, we argue that individuals who have access to, and can draw upon a deeper well of resources would be better able to cope with the stress and uncertainty of job insecurity. This paper focuses on the role of psychological capital as a personal resource. Finally, the paper discusses timely practical implications for organisations regarding how to manage employees' increasing concerns of job insecurity during the global pandemic crisis.

In the remainder of this paper, we first examine the impact of job insecurity on emotional exhaustion. Drawing on Conservation of Resources (COR) theory, we then argue the case for job insecurity rumination as a key mediator in this relationship. Finally, we propose psychological capital as a crucial moderator. Having presented the methodology and key findings, we provide a summary discussion, including implications for practice, limitations and opportunities for future research. 


\section{CONCEPTUAL FRAMEWORK AND HYPOTHESES}

\section{Job insecurity and emotional exhaustion}

Job insecurity refers to employees' subjective perceptions of threats to the future continuity of the current job (Sverke and Hellgren, 2001), which is influenced by environmental threats, such as economic fluctuations, industry decline, and organisational change (e.g., Burke, 1998, Debus et al., 2014). It is subjective in nature with each person having their own interpretation of job insecurity (van Vuuren and Klandermans, 1990; De Witte, 1999), regardless of seemingly being exposed to the same objective environment (Huang et al. 2017).

An important distinction among various conceptualisations of job insecurity is the emphasis on the cognitive (i.e. the risk or likelihood of losing one's job) and affective (i.e. the fear of losing one's job) elements of job insecurity (Jiang and Lavaysse, 2018). Affective job insecurity has been shown to constitute a reaction to cognitive job insecurity (e.g., Huang, Niu, Lee, and Ashford, 2012). Accumulated evidence has shown that cognitive and affective job insecurity are distinct measures capturing different domains of the complex job insecurity phenomenon and thus relate differently to antecedent and outcome variables. We focus on affective job insecurity as it focuses on one's emotional reaction to a judgment of job security rather than a judgement of losing one's job itself. Thus, affective job insecurity is an important indicator of employees affective experiences arising from worry about potential job loss rather than its likelihood. It has been proposed that the affective component of job insecurity best reflects the job insecurity concept (Sverke et al. 2002) and is more closely related to employee outcomes (Probst 2003). One reason for this is due to the fact that awareness of potential job loss does not result in the same reactions as the experience of being emotionally worried about it (Huang et al., 2012). Given the sudden onset of the COVID-19 pandemic and the high unemployment rates at the start, concerns and uncertainty about losing one's job and difficulty attaining new employment may increase worry about financial stability, resulting in poorer employee outcomes (König and Staufenbiel 2006). Hence, affective job insecurity's link to the emotional responses of individuals results in potentially more substantial psychological and behavioural impacts (Sverke et al., 2002).

The focal point of this paper is on the effects of job insecurity on a key psychological reaction, namely emotional exhaustion, which in the past has shown to be positively related to job insecurity (Dekker and Schaufeli, 1995; Bosman et al., 2005). Emotional exhaustion refers to a decrease of emotional and mental energy which causes employees to feel fatigued and overwhelmed due to the depletion of their emotional resources caused by the experience of particular job demands continuously over time (Maslach et al., 2001). In line with Conservation of Resources (COR) theory (Hobfoll, 1989, 2001), job insecurity implies a threat to employees' valuable resources, such as potential loss of job, personal status, and income. Dealing with such a threat is highly stressful and may lead to psychological strain, of which a predominant manifestation is emotional exhaustion (Jiang and Lavaysse, 2018). Based on our theoretical arguments, we predict the following:

Hypothesis 1: Job insecurity will positively relate to emotional exhaustion.

\section{The mediating role of job insecurity rumination}

As noted by previous studies, job insecurity is a complex concept (Shoss, 2017). It is, therefore, essential to comprehend the mechanisms underlying the adverse outcomes of job insecurity. To advance existing research, this study looks at job insecurity rumination. Recently, the concept of rumination has emerged as a critical construct used to understand emotions (Smith and Alloy, 2009). Nolen-Hoeksema and Jackson (2001, p. 37) define rumination as a cognitive process which "engages in a passive focus on one's symptoms of distress and on the possible causes and consequences of these symptoms." In a work-related context, rumination has been referred by Cropley and Zijlstra (2011, p. 10) as "a cognitive state characterised by the appearance of intrusive, pervasive, recurrent thoughts about work, which are negative in affective terms." Consequently, in the case of job insecurity rumination, an individual is repeatedly thinking and worrying about the insecure future of their job which intensifies the initial experience of perceiving job insecurity (Richter et al., 2020).

A clear distinction can be made between ruminating about job insecurity and job insecurity itself as the former refers to "the act of more severe and intensified thinking about the future of the job that has a recurring and repetitive nature (Richter, 2019, p. 3). It can thus be appraised as a stress reaction to the initial threat of job insecurity (Folkman and Lazarus, 1984). Despite the discrepancies in defining the concept, its counterproductive effect on psychological adjustment and interpersonal functioning is commonly accepted among researchers (McCollough et 
al. 2007; Smith and Alloy 2009). Previous studies have shown rumination to be caused by challenging circumstances and uncertainty (Smith and Alloy, 2010), such as job insecurity. We draw on COR theory as a lens to explore the relationship between job insecurity and job insecurity rumination. According to the COR theory (Hobfoll, 1989), resource loss is the primary component in the stress process. Therefore, experiencing job insecurity may cause strain if it is appraised as a threat to resources by the anticipation of, and worry about, losing one's job. This can manifest itself through persistent thoughts about one's possible job loss (Moore et al., 2004). Accordingly, the initial feeling of job insecurity may lead to the cognitive process of ruminating about one's job loss which according to past research has been related to stressful situations (Smith and Alloy, 2010), in this case, the experience of job insecurity.

In this study, rumination is evoked by a problematic situation (i.e. a global pandemic). The process of rumination depends on the certainty of a situation and the quantity of information individuals have access to. The COVID-19 pandemic was unexpected and unprecedented compared to previous events in that there are no clear and established procedures and guidelines to direct employees' behaviours at work thus heightening uncertainty (Lin et al., 2021). The more indications individuals have that something negative is going to happen, the more they ruminate about it (Lyubomirsky et al., 1999). Based on COR theory, the act of rumination may further deplete employees' resources by repetitively thinking about job loss which evokes strain and emotional exhaustion. This is compatible with the notion of exhaustion resulting from impeded recovery after investment of effort in job demands (Perko et al., 2017).

Furthermore, the act of rumination is linked to job stressors and demands as it exacerbates and prolongs distress during the challenging circumstances (Höge et al., 2015). Rumination also interferes with instrumental behaviour, leading to further increases in stressful circumstances. Thus, it can be assumed that it will consequently lead to poor detachment from work and inadequate recovery further impeding an individual's physical and psychological health (Bennett et al., 2018; Verkuil et al., 2010). One explanation for this is the physiological activation caused by persistent pondering over specific stressors. For example, in an experiment carried out by Glynn et al. (2007), participants were asked to carry out a task under pressure which caused stress reactions among participants. When examined a week later, participants who have ruminated about the task presented the same stress reactions as observed directly after the task. This suggests that rumination can prevent psychophysiological recovery, hence mediating the relationship between stressors and their adverse outcomes (Berset et al. 2011). This aligns with the conceptualisation that the persistent worrying about one's situation intensifies the adverse effects of stressful workplace events (Wang et al., 2013). As a result, employees who ruminate about the insecurity of their job can be expected to be more susceptible to emotional exhaustion. We therefore hypothesise the following:

Hypothesis 2: Job insecurity rumination will mediate the relationship between job insecurity and emotional exhaustion.

\section{The moderating role of psychological capital}

Previous studies have highlighted the relationship between job insecurity and employee well-being (e.g. Cheng and Chan, 2008). However, there is not enough known about potential buffering mechanisms that can diminish the effect of job insecurity on well-being (Richter and Näswall, 2018). This paper introduces PsyCap as a resource that can potentially weaken this relationship. PsyCap refers to an individual's positive psychological construct that aligns with positive organisational behaviours, such as effective work performance, commitment, satisfaction and good wellbeing (Avey et al. 2011). It is made up of four components represented by the acronym HERO; hope, (self)-efficacy, resilience and optimism. Hope refers to one's positive motivational state that consists of successful goal-orientated agency and pathways, meaning that individuals with hope exhibit determination to achieve their goals, and have planned pathways to achieve them (Snyder et al. 1991). Self-efficacy is defined as one's confidence in mobilising his or her specific abilities to achieve individual goals (Stajkovic and Luthans, 1998). Resilience, in contrast, relates to an individual's ability to cope with adverse situations and recover from not only stressful situations at work but also positive events (Luthans, 2002). Lastly, optimism reflects a person's positive attributional style to assess difficult situations as temporary impediments, expecting favourable outcomes at the end of the day (Luthans and Youssef, 2004). These four facets of PsyCap have empirically been shown to be a higher-level construct, with the four components having a more significant positive effect than each of them individually (Norman et al. 2010). Hence, PsyCap can be viewed as an essential personal resource, which represents individual's "positive appraisal of circumstances and probability for success based on motivated effort and perseverance" (Luthans et al., 2007, p. 550). A study by Probst et al. (2017) found employees with high levels of PsyCap maintain positive performance 
levels despite their perceived job insecurity. This suggests it can play an essential role as a buffering mechanism by facilitating positive attitudes towards work environments (Paterson et al. 2014). This in turn enables employees to better deal with environmental demands such as job insecurity (Cheung et al. 2011).

To better understand how employees with high personal resources are better equipped to cope with, and control job-related stressors (i.e. job insecurity), we can draw from resource-based models of work stress. As previously mentioned, job distress and exhaustion result primarily from a lack of resources to cope with the demands of work (Demerouti et al. 2001). According to COR theory, employees obtain and retain different types of resources that help them deal with job demands. These potential resources are categorised under four headings; object resources (e.g. house), condition resources (e.g. love) personal resources (e.g. skills and characteristics) and energy resources (e.g. knowledge) (Hobfoll, 2001). As previously mentioned, personal resources refer to personal traits and attributes such as those found in the PsyCap construct. These personal resources facilitate employees to better deal with stressful situations, achieve desired goals and obtain other resources (Hobfoll, 2001). In support of this notion, recent empirical research proposed PsyCap to reduce stress and improve stress responses and coping (Yin et al., 2018; Zhou et al., 2017). Similar to COR theory, the JD-R model suggests that job resources support employees in buffering stressor-strains effects (Demerouti et al. 2001). Therefore, building on the existing literature that has examined positive implications of psychological capital as a resource to deal with adverse outcomes of job insecurity (Costa and Neves, 2017, Bitmis and Ergeneli, 2015) the following hypothesis is put forward:

Hypothesis 3: PsyCap will moderate the positive relationship between job insecurity and emotional exhaustion, such that, when PsyCap is high, the positive relationship between job insecurity and emotional exhaustion will weaken.

See Figure 1 for a representation of the study's theoretical model:

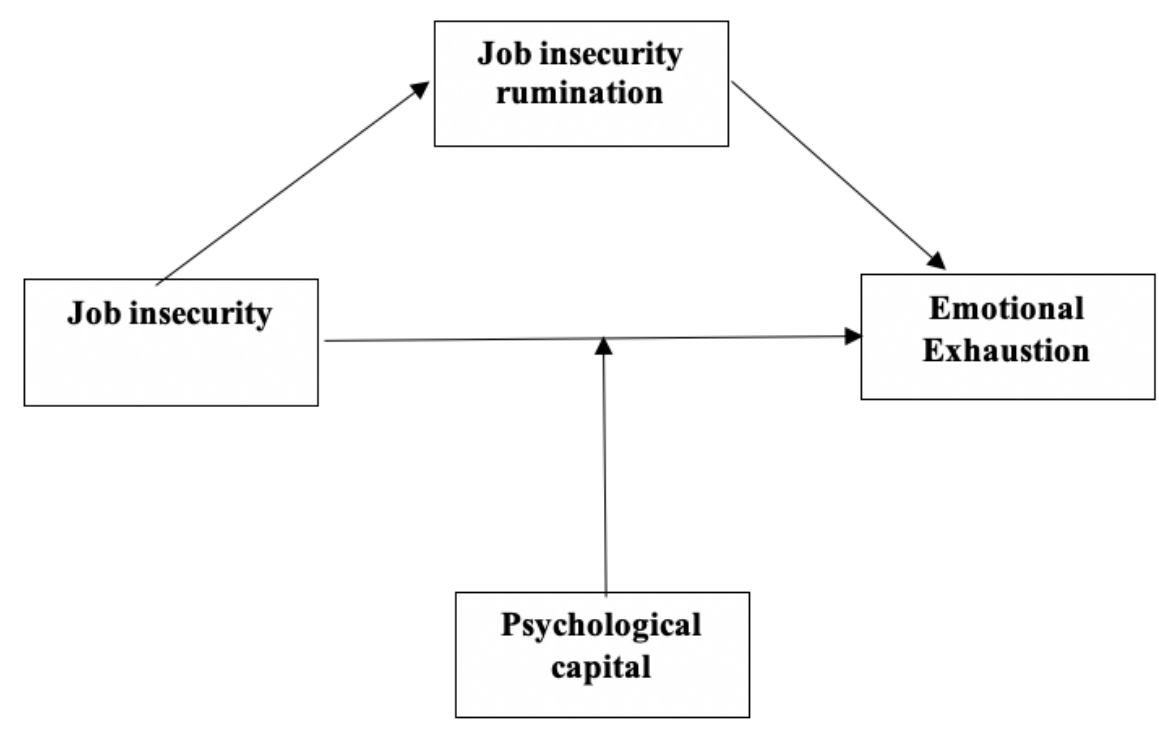

FIGURE 1: Proposed conceptual model

\section{METHOD}

The sample for this study consisted of a cross sectional survey of individuals in the Irish labour market. The main criteria for participation was that the person was employed at the onset of COVID-19. The data was collected in April and May 2020 when Ireland was in the early stages of lockdown with severe restrictions on both business and society. By April 2020, as a result of COVID-19 restrictions, Ireland's standard seasonally adjusted unemployment 
rate went from 4.8 percent in February 2020 to an estimated peak of 28.2 percent, including those in receipt of the Pandemic Unemployment Payment (PUP) (McGuinness and Kelly, 2020). An online survey was distributed via convenience sampling to personal contacts and via social media platforms. In total, 303 participants completed the survey. After the exclusion of 3 incomplete questionnaires, data for the analysis comprised 300 valid surveys. Eighty percent of employees in the sample were female while 62 percent of employees indicated they had been employed in the organisation 5 years or less. Sixty-six percent of participants were aged 35 years or more with almost sixty percent holding a permanent full time contract. Twenty-one sectors are represented in the sample with Healthcare, caring services, social work, personal services (15.3\%) and Education (11.3\%) being the most represented.

\section{Measures}

Unless stated otherwise, each scale measure required a response on a 5-point Likert response scale ranging from 1 (strongly disagree) to 5 (strongly agree).

Job insecurity was measured using a seven-item scale developed by Huang et al. (2010) focusing on workers' affective job insecurity. Sample items included "I am happy with the amount of job security that I have." An overall scale was created with a Cronbach's $\alpha=.94$.

Emotional exhaustion was measured using Maslach and Jackson's emotional exhaustion scale adapted from the Maslach Burnout Inventory (Wright and Cropanzano, 1998). It's a nine-item scale that measures how often one feels emotionally overextended and exhausted by one's work. The inventory uses a 7-point scale $(1=$ never, and 7 = every day). Sample item included "I feel emotionally drained from my work." Cronbach's alpha for this overall scale was .94 .

Job insecurity rumination was measured using a scale developed by Richter et al. (2020). This was adapted from the work of Hermans et al. (2006). The scale consisted of three items (I ruminate about ..(1) that the future of my job is not ensured; (2) that I will be fired; and (3) whether I will be able to keep my job). This scale reports a Cronbach's alpha of .87.

Psychological capital was measured using the Psychological Capital Questionnaire-12 (PCQ-12) which is a shorter version of the Psychological Capital Questionnaire-24 (Luthans et al., 2007) used with the permission of MindGarden.com. The items of the PCQ-12 are structured on a six-point Likert scale (1= strongly disagree, and $6=$ strongly agree), and captured four dimensions: (1). self-efficacy was measured using 3 items; (b) hope was measured using 4 items; (c). optimism was measured using 2 items; (d) resilience was measured using 3 items. Sample items include, "When I have a setback at work, I have trouble recovering from it, moving on" and "Right now I see myself as being pretty successful at work." In this study, the overall scale had a Cronbach's alpha of 0.89 .

\section{Control variables}

We controlled for a number of variables during our analysis which were recoded as dummies: gender ("male" or "female"); age (three categories: "less than 31 years," "greater than 44 years," reference is "31-44 years") and tenure (four categories: "less than 2 years," "2-5 years," "greater than 10 years," reference is "5-10 years") and contract type ("permanent (part-time or full-time) and "other" which includes fixed term, temporary and zero hours' contracts).

\section{Measurement models}

As measures in this dataset were collected from a single source, a series of confirmatory factor analyses were conducted to assess the potential influence of common method bias and to also establish the discriminant validity of the scales (Hair et al., 2009). The four-factor model showed a good model fit: $X 2=71.03$, df $=(48), C F I=0.90$; $\mathrm{TLI}=0.95$; RMSEA $=0.065$. Results of the measurement model comparison demonstrated that the model fit of the alternative models was significantly worse compared to the full measurement model. Hierarchical regression was used to test the proposed direct, mediation, and moderation hypotheses with the help of SPSS PROCESS (version 3.5 developed by Hayes (2017). To examine the mediation hypotheses, we used PROCESS model n.4 and adopted the procedure proposed by Preacher and Hayes (2008), who outline three criteria to justify a mediation effect. Firstly, the independent variable should be significantly associated with the mediator variable. Secondly, after controlling for the effect of the independent variable towards the dependent variable, the relationship between the mediator variable and dependent variable should be significant. Thirdly, the indirect effect from the independent variable to the dependent variable should be significant through a bootstrapping test, which does not require a normal distribution for the concerned variables and can provide a more accurate estimate for the effect size (Hayes, 
2017). Model n1 in PROCESS was used to test the moderation hypothesis. According to Hayes (2017, p. 208): "The effect of an independent variable $X$ on a dependent variable $Y$ is moderated by the variable $M$ if its size, sign or strength depends on or can be predicted by $M$. In that case, $M$ is said to be a moderator of $X$ 's effect on $Y$ or that $\mathrm{X}$ and $\mathrm{M}$ interact in their influence on $\mathrm{Y}^{\prime \prime}$

\section{RESULTS}

Table 1 shows the means, standard deviations, and inter-correlations for all variables. There was no correlation between gender and the key study variables. However, contract type was correlated with job insecurity ( $r=.191$; $p=<0.05)$ as was age $(r=-.113 ; p=<0.05)$ and tenure $(r=.170 ; p=<0.01)$. In accordance with our expectations, job insecurity was positively related to both job insecurity rumination $(r=.787 ; p=<0.01)$ and emotional exhaustion $(r=.381 ; p=<0.01)$. Furthermore, job insecurity rumination was positively correlated with emotional exhaustion ( $r$ $=.413 ; p=<0.01)$. PsyCap was negatively correlated with both job insecurity $(=-0.257, p=<0.01)$ and emotional exhaustion $(r=-.315, p=<0.01)$.

\section{Test of Hypotheses}

Table 2 shows results for hypotheses 1 and 2. Our results demonstrate that job insecurity was positively related to emotional exhaustion $(\beta=0.498, p<0.001$ ) thus, Hypothesis 1 was supported. Hypothesis 2 proposed that job insecurity rumination mediates the relationship between job insecurity and emotional exhaustion. Results show that job insecurity was significantly related to the mediator, job insecurity rumination $(\beta=.680, p<0.001)$. Job insecurity rumination was significantly associated with emotional exhaustion $(\beta=.415, p<0.001)$. Finally, when both the independent and mediator variables are put into the model together, the independent variable, job insecurity, was no longer significant $(\beta=.216, p=n s)$. The $95 \%$ bias-corrected confidence interval $(\mathrm{Cl})$ for the indirect effect did not overlap with zero $(.1079, .4579)$. Thus, we so found support for full mediation for Hypothesis 2.

Table 1: Descriptive statistics, correlations, and scale reliabilities for study variables

\begin{tabular}{|c|c|c|c|c|c|c|c|c|c|c|c|}
\hline & & Mean & SD & 1 & 2 & 3 & 4 & 5 & 6 & 7 & 8 \\
\hline 1 & Gender & & & - & & & & & & & \\
\hline 2 & Age & & & 0.29 & - & & & & & & \\
\hline 3 & Tenure & & & .065 & $.410^{\star \star}$ & - & & & & & \\
\hline 4 & Contract & & & -.031 & $-.124^{\star}$ & $-.173^{\star \star}$ & - & & & & \\
\hline 5 & ال ال & 2.79 & 1.23 & -.018 & $-.113^{\star}$ & $-.170^{\star \star}$ & $.191^{*}$ & $(.94)$ & & & \\
\hline 6 & JI Rum & 2.09 & 1.06 & -.051 & $-.150^{\star *}$ & $-.176^{\star \star}$ & .110 & $.687^{\star \star}$ & (.86) & & \\
\hline 7 & PsyCap & 4.38 & .810 & -.016 & $.256^{\star \star}$ & $.131^{\star}$ & $-.153^{\star *}$ & $-.256^{\star *}$ & $-.277^{\star *}$ & (.89) & \\
\hline 8 & $\mathrm{EE}$ & 3.59 & 1.57 & -.002 & $-.115^{\star}$ & -.035 & .026 & $.381^{* *}$ & $.413^{* *}$ & $-.315^{\star *}$ & (.94) \\
\hline
\end{tabular}

Note. $n=300$. Cronbach alpha values for each scale are reported on the diagonal in italics. $\mathrm{Jl}=\mathrm{J}$ ob insecurity; $\mathrm{J}$ Rum $=\mathrm{J}$.b insecurity rumination; PsyCap = Psychological capital; EE = Emotional exhaustion. Gender (Male = 1); Age (31-44 years $=1)$; Tenure $(<5$ years $=1)$; Contract $($ Permanent $=1) .{ }^{*} p<0.05 ;{ }^{*} p<0.01$

This study further hypothesised that the strength of the relationship between job insecurity (IV) and emotional exhaustion (DV) would lessen with the presence of high PsyCap (moderator). To test hypothesis 3, all variables were standardised, and a moderation test was carried out using model $1 \mathrm{in}$ PROCESS. The results for the regression testing for the moderation of PsyCap are presented in Table 3. The analysis did not demonstrate a significant job insecurity $x$ PsyCap interaction on emotional exhaustion $(\beta=.052, \mathrm{Cl}[-.1202, .2240], \mathrm{p}=.553)$ thus hypothesis 3 was not supported. 
Table 2: Regression results for mediation

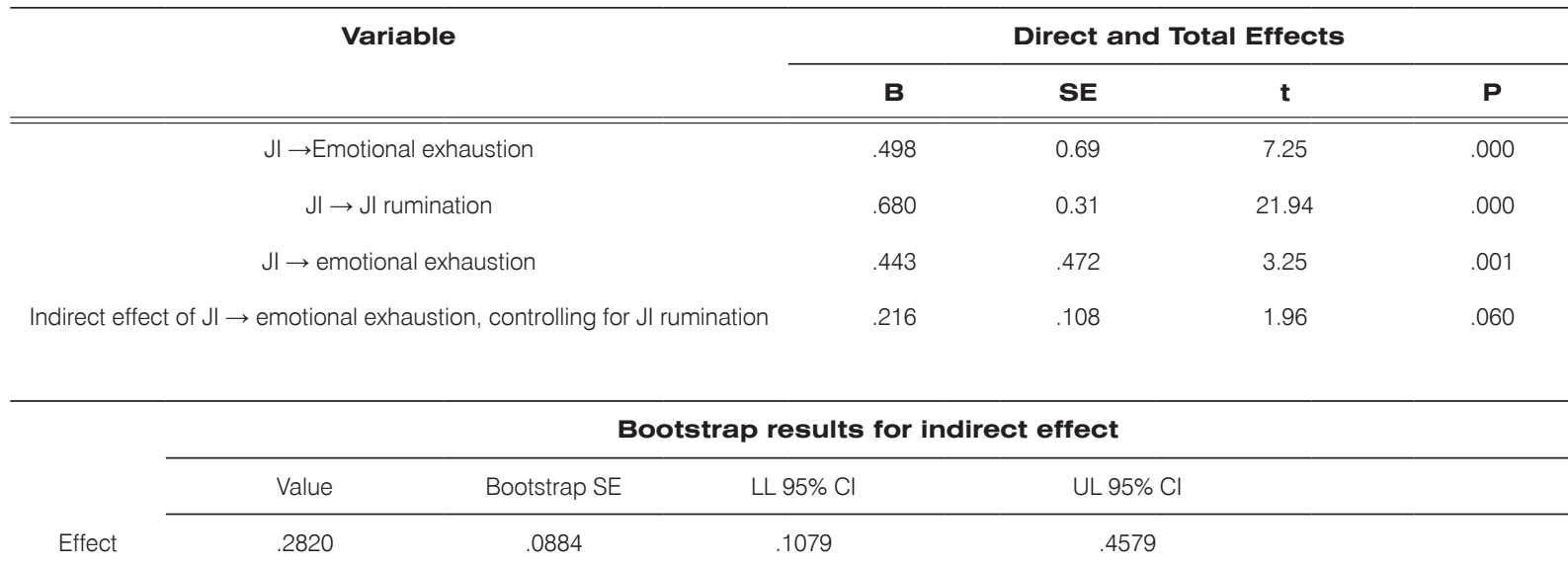

Note: Unstandardized regression coefficients. Bootstrap sample size - 5000. LL - lower limit, $\mathrm{Cl}=$ Confidence interval, $\mathrm{UL}=$ upper limit. $\mathrm{Jl}=\mathrm{Job}$ insecurity; Jl rumination = Job insecurity rumination.

Table 3: Regression Results for conditional indirect effects

\section{Dependent variable: Emotional Exhaustion}

\begin{tabular}{|c|c|c|c|c|c|c|}
\hline & B & SE & $\mathbf{t}$ & $\mathbf{p}$ & LLCI & ULCI \\
\hline ال & .193 & .392 & .4910 & .623 & -.5799 & .965 \\
\hline PsyCap & -.595 & .269 & -2.210 & .027 & -1.124 & -.065 \\
\hline Jl x PsyCap & .052 & .087 & .593 & .553 & -.1202 & .224 \\
\hline
\end{tabular}

Note: $\mathrm{Cl}=$ confidence interval; $\mathrm{LL}=$ Lower limit; UL = Upper limit. Bootstrap sample = 5000. Jl = job insecurity; PsyCap = psychological capital

\section{DISCUSSION}

The aim of the present study has been to investigate the relationship between job insecurity and emotional exhaustion during the COVID-19 pandemic. A key contribution of the study was the broadening of our understanding of the relationship between job insecurity and emotional exhaustion through examining a new mechanism, namely job insecurity rumination. Results indicated that job insecurity was positively related to emotional exhaustion. This is consistent with past research that has established job insecurity as a work-related stressor leading to impaired wellbeing among employees experiencing job insecurity (Cheng and Chan, 2008; Sverke et al., 2002). In the context of COVID-19, consequences of job insecurity can be assigned to employees negatively evaluating the current situation and perceiving the future as uncertain due to the ongoing pandemic. The perception of losing job security forces them to shift their focus toward their existing resources in attempts to reduce the risk of possibly losing their job (Hobfoll, 1989; Staufenbiel and König, 2010). Correlations suggest that employees on temporary or fixed contracts experienced higher affective job insecurity and higher job insecurity rumination than those on permanent contracts. Previous research shows that job insecurity is a significant and inherent feature of temporary employment arrangements and during COVID-19 those sectors who use these temporary employment arrangements (retail and hospitality in particular) were most impacted. An OECD report (OECD 2020) suggests that temporary and selfemployed workers were hardest hit by the pandemic, followed closely by young people. We know that job insecurity 
can be a more severe stressor for men than women (De Witte, 1999). However, this was not supported in this research though, we acknowledge our sample was dominated by female responses.

Given that emotional exhaustion has been linked to significant employee outcomes such as job performance and organisational behaviour citizenship (Cropanzano et al., 2003) understanding further the nuances of the association between job insecurity and emotional exhaustion is crucial in order to limit its further impact on the organisation. Rumination about job insecurity was introduced as a way to explain the impact of job insecurity on emotional exhaustion. In the field of organisational science there is limited empirical research that looks at rumination in the context of work, and as noted by Richter et al. (2020) specific job insecurity rumination in the context of the job insecurity-outcome relationship has only recently been investigated. The results of this study supported the hypothesis of the mediating function job insecurity rumination plays between job insecurity and emotional exhaustion. In line with COR theory, employees experience a stress reaction as a result of perceptions of job insecurity and may ruminate about their job insecurity as a result. The mediating effect of job insecurity rumination can be explained by the role it plays as a strain based mechanism in intensifying the experience of job insecurity which in turn leads to depletion of an employee's existing resources and subsequent emotional exhaustion. This is in line with research dealing with work-related rumination which found it to be the cause of impaired well-being (Weigelt et al., 2019). In the context of COVID-19, job insecurity rumination may be a result of a coping mechanism that is evoked by the stress reaction caused by uncertainty about the future (Richter et al., 2013). Furthermore, it has been noted that the more it is suggested to individuals that something negative is going to happen, the more they will ruminate about it (Lyubomirsky et al., 1999). Employees' continuous exposure to COVID-19 media news around its impact on the economy in particular would have further fostered their rumination by "repetitively and passively focusing on symptoms of distress and on the possible causes and consequences of these symptoms" (Kniffin et al., 2021, p. 68).

We also proposed the moderating role of PsyCap on the relationship between job insecurity and emotional exhaustion. This assumption was based on previous COR research that has demonstrated the buffering effects of PsyCap as a resource to deal with various adverse outcomes of job insecurity (Costa and Neves, 2017) as well as its association with reducing detrimental health and personal outcomes (Avey et al., 2014). This hypothesis was not supported. One possible reason for the failure in supporting the moderating role of PsyCap in this study can be explained through matching theory. Daniels and de Jonge (2010) argue that job demands, job resources and job strains each contain cognitive, emotional and physical elements and it is therefore important to consider the nature of each when testing moderating effects. Based on the matching theory, the moderating effect is less likely to result when the nature of the resource does not match the strain. Since this study investigates a cognitive resource (PsyCap) and emotional strain (emotional exhaustion) the lack of support for the moderating hypothesis seems to support the above theory. Building on this argument, some authors have emphasised that the continued use of individual resources such as PsyCap to deal with stressful situations could result in resource deterioration (Hobfoll, 2001). In the unprecedented COVID context, it could be argued that the PsyCap resources available to a person, even if they are adequate, were not enough to alleviate the strain of the job insecurity-emotional exhaustion relationship. Furthermore, drawing from previous research, this study conceptualised PsyCap as a personal resource that can buffer the effects of job demands (Mayerl et al., 2016), however, some studies theorise that personal resources influence the perception of job demands and resources rather than act as moderators (Schaufeli and Taris, 2014; Grover et al., 2018). Lastly, PsyCap has been said to relate to the "aspects of the self that are generally linked to resiliency and refer to individuals' sense of their ability to control and impact upon their environment successfully" (Xanthopoulou et al., 2007, pp. 123-124). This study took place during unprecedented times and was surrounded by the uncertainty caused by the COVID-19 virus. As a result, it is possible that although participants demonstrated levels of PsyCap, they did not have a sense of being able to control one's environment as much of the work-related and every-day decisions among employers and employees was dictated by the virus. As one participant put it "there are changes to the structure very often which can be difficult to adjust knowing that it will change again soon."

\section{Practical implications}

This study has important practical implications for organisations. We acknowledge that organisations themselves were experiencing similar uncertainties as employees as a result of COVID-19 and so national level policies were critical to support employees. In the context of the COVID-19 crisis, Government communication (e.g. through National Public Health Emergency Team (NPHET) briefings) played a crucial role in increasing public awareness 
of the virus and in facilitating public trust and confidence. Demonstration by the government of a strong policy intention to support employees and companies during the pandemic was also critical to providing a clear message of certainty. It is reported that more than a third of Ireland's workforce had its income substantially supported by the state (through PUP and TWSS) since the crisis started in March 2020 (McGann et al., 2020). This highlights the role of the welfare state as a social and economic shock absorber to help ease job insecurity and reduce redundancies.

For employers, it is imperative they acknowledge employees fears and ensure clear communication to reduce the uncertainty surrounding their future employment (Sverke and Hellgren, 2002). This communication will occur in tandem with Government communication as the pandemic evolves through stages. It may not be able to provide complete certainty on the future, but they can provide employees with consistent and accurate information about how the pandemic is affecting the company and employees via official channels (e.g., emails, newsletters). Communication becomes even more important given the majority of staff are working from home and are not in the office. Doing so may be a resource to help reduce uncertainty and feelings of job insecurity and rumination on job insecurity. Informational justice (Colquitt, 2001) which focuses on interactional and informational justice should be a priority for all managers in order to reduce uncertainty amongst their staff (Yoon et al., 2021). They can do this by ensuring frequent and transparent information and communication with employees via team briefings for example. This can also give employees a sense of control and support as they are kept aware of what is going on in the organisation which can ameliorate the negative effects of job insecurity as it can be used as a resource to enhance their coping efforts. Finally, managers should communicate with empathy, encourage wellness resources, and offer practical support for employees' well-being.

\section{Limitations and future research}

The findings reported here should be interpreted in light of some limitations, each indicating clear directions for future research. Firstly, the nature of the study was cross-sectional due to time and resources constraints. As a result, knowledge of the long-term effects of job insecurity and how the adverse outcomes develop over time is limited. Previous studies have indicated that individuals who experience job insecurity over a long period experience more substantial adverse effects than those who are affected for a shorter amount of time (Heaney et al., 1994). The data for this research was collected at the early stages of the COVID-19 pandemic during Irelands first lockdown. As the pandemic has evolved through phases, Ireland has experienced further lockdowns and greater periods of uncertainty. Consequently, future research should look into how job insecurity and job insecurity rumination relates to employee outcomes by employing a longitudinal design to address the ongoing impact of COVID-19 on job insecurity. Furthermore, future research would benefit from exploring how demographics influence job insecurity and job insecurity rumination specifically age, contract type and gender differences. Previous research suggests women appear more likely than men to engage in rumination when sad or depressed (Nolen-Hoeksema and Jackson, 2001). Future research is needed to explore if there are gender differences in employees' experiences of, and response to, job insecurity through rumination.

A second limitation is the use of a convenience sample in data collection which makes it difficult to extrapolate findings beyond the parameters of the study. Thus, it is recommended that future research be conducted with the use of more representative random samples in order to make generalizations. Lastly, the current study only looked at the affective component of the job insecurity construct. Past studies have postulated the importance of distinguishing cognitive versus affective job insecurity (Borg and Elizur, 1992). Individuals who perceive job insecurity do not necessarily have to have affective responses towards job insecurity (Probst, 2003). Thus, future studies might benefit from integrating the cognitive element of job insecurity in order to determine how job insecurity rumination is associated with it. Similarly, this study was only concerned with the unidimensional aspect of job insecurity. In light of the current situation caused by COVID-19 many organisations were forced to restructure their operations in efforts to adapt. One immediate consequence was the redesign of some jobs. As a result, it may be more appropriate to study job insecurity during the pandemic under the multidimensional conceptualisation, which extends beyond concern over job loss by including the loss of desirable job features, such as current working conditions (Ashford et al., 1989).

In regards to other possible future research, an interesting point was made by one of the participants who noted that as a member of a trade union, he has never experienced job insecurity. It would be interesting to see how this statement relates to a larger population in the context of economic uncertainty caused by the pandemic. It would also contribute to the job insecurity research from the perspective of employment relations. Studies have shown that union membership may decrease the effects of job insecurity through their collective voice (Sverke and Hellgren, 
2001). Nevertheless, there is limited research on how union support affects experiences of job insecurity (Sverke et al., 2006), and thus future research is necessary.

\section{CONCLUSION}

Past research has established job insecurity as a work-related stressor that leads to poor employee well-being (cf. Cheng and Chan, 2008). However, a dominant number of studies have ignored the distinction between the cognitive and affective constructs of job insecurity (Shoss, 2017). By solely employing the affective conceptualisation of job insecurity, this study has contributed to the conceptual development of job insecurity (Jiang and Lavaysse, 2018). The primary purpose of this study was to extend the existing knowledge of the relationship between job insecurity and its consequences. It thus investigated a new explanatory mechanism underlying the relationship between job insecurity and emotional exhaustion. Specifically, the objective was to examine job insecurity rumination as a mediator to amplify the understanding of how the experience of job insecurity can contribute to emotional exhaustion. Furthermore, this study aimed to examine the role of personal resources, namely PsyCap, as a buffering mechanism that can minimise and weaken the relationship between job insecurity and emotional exhaustion. It cannot be argued that the results are conclusive, and one should be cautious when interpreting them due to the sample used in this study. They do imply, however, the substantial role of job insecurity rumination in the job insecurity-emotional exhaustion relationship in the context of economic uncertainty caused by the COVID-19 pandemic. Since physical and psychological health is critical for organisation's performance (Ford et al., 2011), the results help organisations faced with economic ambiguity to understand better what to be aware of when attempting to preserve employees' well-being by preventing employees from ruminating about job insecurity.

\section{NOTE ON CONTRIBUTORS}

Marta Konkel is a HR practitioner and former MSc in Human Resource Management student at Dublin City University. Margaret Heffernan is Associate Professor of Human Resource Management at Dublin City University. Her areas of research include compassion at work, employee wellbeing and Strategic HRM.

\section{References}

Adkins, C.L., Werbel, J.D. and Farh, J.L. (2001). A field study of job insecurity during a financial crisis. Group \& Organization Management, 26(4), 463483.

Ashford, S.J., Lee, C. and Bobko, P. (1989). Content, cause, and consequences of job insecurity: $A$ theory-based measure and substantive test. Academy of Management Journal, 32(4), 803-829.

Altig, D., Baker, S., Barrero, J.M., Bloom, N., Bunn, P., Chen, S., Davis, S.J., Leather, J., Meyer, B., Mihaylov, E. and Mizen, P., 2020. Economic uncertainty before and during the COVID-19 pandemic. Journal of Public Economics, 191, 104274.

Avey, J.B., Reichard, R.J., Luthans, F. and Mhatre, K.H. (2011). Meta $\square$ analysis of the impact of positive psychological capital on employee attitudes, behaviors, and performance. Human Resource Development Quarterly, 22(2), 127-152.
Balliester T and Elsheikhia A. (2018) The future of work: a literature review. Working Paper No. 29. Geneva, Switzerland: International Labour Organization.

Bennett, A.A., Bakker, A.B. and Field, J.G. (2018). Recoveryfromwork $\square$ relatedeffort:Ameta $\square$ analysis. Journal of Organizational Behavior, 39(3), 262-275.

Berset, M., Elfering, A., Lüthy, S., Lüthi, S. and Semmer, N.K. (2011). Work stressors and impaired sleep: Rumination as a mediator. Stress and Health, 27(2), 71-82.

Bitmis, M.G. and Ergeneli, A. (2015). How psychological capital influences burnout: the mediating role of job insecurity. Procedia-Social and Behavioral Sciences, 207, 363-368.

Borg, I. and Elizur, D. (1992). Job insecurity: Correlates, moderators and measurement. International Journal of Manpower. 13(2), 13-26.

Bosman, J., Rothmann, S. and Buitendach, J.H. (2005). Job insecurity, burnout and work engagement: 
the impact of positive and negative effectivity. $S A$ Journal of Industrial Psychology, 31(4), 48-56.

Cheng, G.H.L. and Chan, D.K.S. (2008). Who suffers more from job insecurity? A meta $\square$ analytic review. Applied Psychology, 57(2), 272-303.

Cheung, F., Tang, C.S.-k. and Tang, S. (2011). Psychological capital as a moderator between emotional labor, burnout, and job satisfaction among school teachers in China. International Journal of Stress Management, 18(4), 348-371.

Coates, D., Byrne, S., Brioscú, A., Corcoran, D., Cronin, H., Keenan, E. and Mclndoe-Calder, T. (2020). The Initial Impacts of the COVID-19 Pandemic on Ireland's Labour Market. Working paper. Department of Employment Affairs and Social Protection.

Colquitt, J.A. (2001). On the dimensionality of organizational justice: a construct validation of a measure. Journal of Applied Psychology, 86(3), 386-400.

Costa, S. and Neves, P. (2017). Job insecurity and work outcomes: The role of psychological contract breach and positive psychological capital. Work \& Stress, 31(4), 375-394.

Cropley, M. and Zijlstra, F.R. (2011). Work and rumination. In Cooper, C.L. and Langan-Fox, J. eds., Handbook of Stress in the Occupations. Edward Elgar., p.503.

Daniels, K. and De Jonge, J. (2010). Match making and match breaking: The nature of match within and around job design. Journal of Occupational and Organizational Psychology, 83(1), 1-16.

De Witte, H. D. (1999). Job Insecurity and Psychological Well-being: Review of the Literature and Exploration of Some Unresolved Issues. European Journal of Work and Organizational Psychology, 8(2), 155-177.

Dekker, S.W. and Schaufeli, W.B. (1995). The effects of job insecurity on psychological health and withdrawal: A longitudinal study. Australian Psychologist, 30(1), 57-63.

Demerouti, E., Bakker, A. B., Nachreiner, F. and Schaufeli, W. B. (2001). The Job DemandsResources model of burnout. Journal of Applied Psychology, 86, 499-512.

Folkman, S. and Lazarus, R.S. (1984). Stress, appraisal, and coping. New York: Springer Publishing Company.

Ford, M.T., Cerasoli, C.P., Higgins, J.A. and Decesare, A.L. (2011). Relationships between psychological, physical, and behavioural health and work performance: A review and meta-analysis. Work \& Stress, 25(3), 185-204.
Glynn, L.M., Christenfeld, N. and Gerin, W. (2007). Recreating cardiovascular responses with rumination: The effects of a delay between harassment and its recall. International Journal of Psychophysiology, 66(2), 135-140.

Grover, S.L., Teo, S.T., Pick, D., Roche, M. and Newton, C.J. (2018). Psychological capital as a personal resource in the JD-R model. Personnel Review. 47(4), 968-984.

Hayes, A. (2017). Introduction to Mediation, Moderation, and Conditional Process Analysis: A RegressionBased Approach. (2nd Ed). Guilford Press.

Heaney, C.A., Israel, B.A. and House, J.S. (1994). Chronic job insecurity among automobile workers: Effects on job satisfaction and health. Social science \& medicine, 38(10), 1431-1437.

Hermans, D., Van den Bergh, O., Philippot, P., De Bruyn, E., Antonissen, D., and Taeymans, S. (2006). Piekeren over het werk: symptoom of mechanisme, bewuste inhoud of onbewust proces? [Ruminating about work: symptom or mechanism, conscious content or unconscious process?]. Paper Presented at the Najaarscongres of the Vereniging voor Gedragstherapie en Cognitieve Therapie, Veldhoven

Hobfoll, S. E. (2001). The influence of culture, community, and the nested $\square$ self in the stress process: Advancing conservation of resources theory. Applied Psychology: An International Review, 50, 337-421.

Hobfoll, S.E. (1989). Conservation of resources: A new attempt at conceptualizing stress. American Psychologist, 44(3), 513.

Höge, T., Sora, B., Weber, W.G., Peiró, J.M. and Caballer, A. (2015). Job insecurity, worries about the future, and somatic complaints in two economic and cultural contexts: A study in Spain and Austria. International Journal of Stress Management, 22(3), 223-242.

Huang, G.H., Lee, C, Ashford, S., Chen, Z. and Ren, X. (2010). Affective job insecurity: a mediator of the cognitive job insecurity and employee outcomes relationships. International Studies of Management \& Organization, 40(1), 20-39.

Huang, G.H., Niu, X., Lee, C. and Ashford, S.J. (2012). Differentiating cognitive and affective job insecurity: Antecedents and outcomes. Journal of Organizational Behavior, 33(6), 752-769.

Huang, G.H., Wellman, N., Ashford, S.J., Lee, C. and Wang, L. (2017). Deviance and exit: The organizational costs of job insecurity and moral disengagement. Journal of Applied Psychology, 102(1), 26. 
Jiang, L. and Lavaysse, L.M. (2018). Cognitive and affective job insecurity: A meta-analysis and a primary study. Journal of Management, 44(6), 2307-2342.

Kniffin, K.M., Narayanan, J., Anseel, F., Antonakis, J., Ashford, S.P., Bakker, A.B., Bamberger, P., Bapuji, H., Bhave, D.P., Choi, V.K. and Creary, S.J. (2021). COVID-19 and the workplace: Implications, issues, and insights for future research and action. American Psychologist, 76(1), 63.

Lee, C., Huang, G.-H., Ashford, S.J. (2018). Job Insecurity and the Changing Workplace: Recent Developments and the Future Trends in Job Insecurity Research. Annual Review of Organizational Psychology and Organizational Behavior 5, 335-359.

Lin, W., Shao, Y., Li, G., Guo, Y. and Zhan, X. (2021). The psychological implications of COVID-19 on employee job insecurity and its consequences: The mitigating role of organization adaptive practices. Journal of Applied Psychology, 106(3), p.317.

Luthans, F. and Youssef, C.M. (2004). Human, social, and now positive psychological capital management: Investing in people for competitive advantage, Organizational Dynamics, 33(2), 143160.

Luthans, F. (2002). Positive organizational behavior: Developing and managing psychological strengths. Academy of Management Perspectives, 16(1), 5772.

Luthans, F., Avolio, B.J., Avey, J.B. and Norman, S.M. (2007). Positive psychological capital: Measurement and relationship with performance and satisfaction. Personnel Psychology, 60(3), 541-572.

Lyubomirsky, S., Tucker, K.L., Caldwell, N.D. and Berg, K. (1999). Why ruminators are poor problem solvers: Clues from the phenomenology of dysphoric rumination. Journal of Personality and Social Psychology, 77(5), 1041.

Maslach, C., Schaufeli, W.B. and Leiter, M.P. (2001). Job burnout. Annual Review of Psychology, 52(1), 397-422.

Mayerl, H., Stolz, E., Waxenegger, A., Rásky, É. and Freidl, W. (2016). The role of personal and job resources in the relationship between psychosocial job demands, mental strain, and health problems. Frontiers in Psychology, 7, 1214.

McGann, M., Murphy, M.P. and Whelan, N. (2020). Workfare redux? Pandemic unemployment, labour activation and the lessons of post-crisis welfare reform in Ireland. International Journal of Sociology and Social Policy, 40(9/10), 963-978.
McGuinness, S. and Kelly, E. (2020). Managing mass unemployment flows during the COVID-19 pandemic. ESRI survey and statistical report series No. 95 July.

Moore, S., Grunberg, L. and Greenberg, E. (2004). Repeated downsizing contact: the effects of similar and dissimilar layoff experiences on work and wellbeing outcomes. Journal of Occupational Health Psychology, 9(3), 247.

Nolen-Hoeksema, S. and Jackson, B. (2001). Mediators of the gender difference in rumination. Psychology of Women Quarterly, 25(1), 37-47.

Nolen-Hoeksema, S., Wisco, B.E. and Lyubomirsky, S. (2008). Rethinking rumination. Perspectives on psychological science, 3(5), 400-424.

Norman, S.M., Avey, J.B., Nimnicht, J.L., and Pigeon, N.G. (2010). The interactive effects of psychological capital and organizational identity on employee organizational citizenship behaviors. Journal of Leadership \& Organizational Studies, 17, 380-391.

OECD (2020). OECD Employment Outlook 2020: Worker Security and the COVID-19 Crisis. Paris: OECD.

Paterson, T.A., Luthans, F. and Jeung, W. (2014). Thriving at work: impact of psychological capital and supervisor support. Journal of Organizational Behavior, 35(3), 434-446.

Perko, K., Kinnunen, U. and Feldt, T. (2017) Long-term profiles of work related rumination associated with leadership, job demands, and exhaustion: A threewave study, Work \& Stress, 31(4), 395-420.

Preacher, K. J. and Hayes, A. F. (2008). A symptotic and resampling strategies for assessing and comparing indirect effects in multiple mediator models. Behavior Research Methods, 40, 879-891. doi: 10.3758/BRM.40.3.879.

Probst, T.M. (2003). Development and validation of the job security index and the job security satisfaction scale: A classical test theory and IRT approach. Journal of Occupational and Organizational Psychology, 76(4), 451-467.

Probst, T.M., Gailey, N.J., Jiang, L. and Bohle, S.L. (2017). Psychological capital: Buffering the longitudinal curvilinear effects of job insecurity on performance. Safety Science, 100, 74-82.

Richter, A., Näswall, K., De Cuyper, N., Sverke, M., De Witte, H. and Hellgren, J. (2013). Coping with job insecurity. Career Development International, 18(5), 484-502.

Richter, A. and Näswall, K. (2019). Job insecurity and trust: Uncovering a mechanism linking job insecurity to well-being. Work \& Stress, 33(1), 2240. 
Richter, A., Vander Elst, T. and De Witte, H. (2020). Job Insecurity and Subsequent Actual Turnover: Rumination as a Valid Explanation? Frontiers in Psychology, 11, 712.

Schaufeli, W.B. and Taris, T.W. (2014). A critical review of the job demands-resources model: Implications for improving work and health. In G. Bauer and O. Hämmig (Eds). Bridging Occupational, Organizational and Public Health (pp. 43-68). Springer, Dordrecht.

Shoss, M.K. (2017). Job insecurity: An integrative review and agenda for future research. Journal of Management, 43(6), 1911-1939.

Smith, J.M. and Alloy, L.B. (2009). A roadmap to rumination: A review of the definition, assessment, and conceptualization of this multifaceted construct. Clinical Psychology Review, 29(2), 116-128.

Stajkovic, A. D. and Luthans, F. (1998). Self-efficacy and work-related performance: A meta-analysis. Psychological Bulletin, 124, 240-261.

Staufenbiel, T. and König, C.J. (2010). A model for the effects of job insecurity on performance, turnover intention, and absenteeism. Journal of Occupational and Organizational Psychology, 83(1), 101-117.

Sverke, M. and Hellgren, J. (2001). Exit, voice and loyalty reactions to job insecurity in Sweden: do unionized and non $\square$ unionized employees differ? British Journal of Industrial Relations, 39(2), 167182.

Sverke, M., Hellgren, J. and Näswall, K. (2002). No security: a meta-analysis and review of job insecurity and its consequences. Journal of Occupational Health Psychology, 7(3), 242.

Sverke, M., Hellgren, J. and Näswall, K. (2006). Job insecurity: A literature review. Arbetslivs institutet: Sweden.

Van Vuuren, C.V. and Klandermans, P.G. (1990). Individual reactions to job insecurity: An integrated model. In Drenth, P.J., Sergeant, J.A., Takens, R.J. (Eds.), European perspectives in psychology, (pp. 133-146). Oxford: Wiley.
Verkuil, B., Brosschot, J.F., Gebhardt, W.A. and Thayer, J.F. (2010). When worries make you sick: a review of perseverative cognition, the default stress response and somatic health. Journal of Experimental Psychopathology, 1(1), 87-118.

Wang, M., Liu, S., Liao, H., Gong, Y., Kammeyer-Mueller, J. and Shi, J. (2013). Can't get it out of my mind: Employee rumination after customer mistreatment and negative mood in the next morning. Journal of Applied Psychology, 98(6), 989.

Weigelt, O., Syrek, C.J., Schmitt, A. and Urbach, T. (2019). Finding peace of mind when there still is so much left undone-A diary study on how job stress, competence need satisfaction, and proactive work behavior contribute to work-related rumination during the weekend. Journal of Occupational Health Psychology, 24(3), 373.

Wright, T.A. and Cropanzano, R. (1998). Emotional exhaustion as a predictor of job performance and voluntary turnover. Journal of Applied Psychology, 83(3), 486.

Xanthopoulou, D., Bakker, A.B., Demerouti, E. and Schaufeli, W.B. (2007). The role of personal resources in the job demands-resources model. International Journal of Stress Management, 14(2), 121.

Yin, H., Wang, W., Huang, S. and Li, H. (2018). Psychological capital, emotional labor and exhaustion: Examining mediating and moderating models. Current Psychology, 37(1), 343-356.

Yoon, S., McClean, S. T., Chawla, N., Kim, J.K., Koopman, J., Rosen, C.C., Trougakos, J.P. and McCarthy, J.M. (2021). Working through an "infodemic": The impact of COVID-19 news consumption on employee uncertainty and work behaviors. Journal of Applied Psychology, 106(4), p.501.

Zhou, H., Peng, J., Wang, D., Kou, L., Chen, F., Ye, M., Deng, Y., Yan, J. and Liao, S. (2017). Mediating effect of coping styles on the association between psychological capital and psychological distress among Chinese nurses: a cross $\square$ sectional study. Journal of Psychiatric and Mental Health Nursing, 24(2-3), pp.114-122. 